\title{
Perception about Etiology of Epilepsy and Help-Seeking Behavior in Patients with Epilepsy
}

\author{
Gautam Das ${ }^{1}$ Samar Biswas ${ }^{1} \quad$ Souvik Dubey ${ }^{1}$ Durjoy Lahiri ${ }^{1} \quad$ Biman Kanti Ray ${ }^{1} \quad$ Alak Pandit $^{1}$ \\ Sankar Prasad Saha ${ }^{2}$ Atanu Biswas ${ }^{1, \odot}$ \\ 1Department of Neurology, Bangur Institute of Neurosciences, \\ Institute of Post Graduate Medical Education \& Research, Kolkata, \\ West Bengal, India \\ 2Department of Neurology, Nil Ratan Sarkar Medical College, \\ Kolkata, West Bengal, India
}

Int J of Epilep 2021;7:22-28.

\begin{abstract}
Objectives Patients with epilepsy and their family have diverse beliefs about the cause of their illness that generally determine their treatment-seeking behavior. In this study, our aim was to find out different beliefs about epilepsy that lead to different help-seeking patterns, which act as barrier to the intended modern medical management of epilepsy.

Materials and Methods One hundred and fifty consecutive consenting patients accompanied by a reliable informant/family member fulfilling the International Classification of Epileptic Seizures (ICES), simplified version, were included. Demographic and clinical data of all the eligible subjects was collected. Perceived cause of illness and help-seeking pattern were explored from patient/informant by administering proper instruments.

Results Respondents identified varied causes of epilepsy and explored multiple

Keywords

- epilepsy

- perception

- behaviour

- stigma

- supernatural help-seeking options before reaching tertiary care centers. We observed that, generally, epileptic patients/relatives who had belief in causes like supernatural causes sought help from nonprofessional personnel and those attributed their symptom to bodily pathology had professional help-seeking.

Conclusions The belief in supernatural causes not being conformed to the biomedical models of the epileptic disorders increases the treatment gap.
\end{abstract}

\section{Introduction}

The knowledge and perception regarding the nature and cause of epilepsy among the general public are variable. ${ }^{1}$ In developing countries, a vast majority of people attribute epileptic symptoms as supernatural phenomena, which contradict the biomedical model of epilepsy envisaged by modern epileptologists.-5

published online July 30, 2021
DOI https://doi.org/ 10.1055/s-0041-1731933 ISSN 2213-6320
Perceptions of the sufferer about the cause of epilepsy as well as the perception about others' reaction toward their sufferings influence the choice of treatment and its outcome. ${ }^{6}$

People suffering from epilepsy often do not seek professional help. Reasons for this include negative attitudes toward the help available, as well as concerns about cost of treatment, transportation, or inconvenience, fear of breach in confidentiality, and feeling like they can handle the problem

(C) 2021. Indian Epilepsy Society.

This is an open access article published by Thieme under the terms of the Creative Commons Attribution-NonDerivative-NonCommercial-License, permitting copying and reproduction so long as the original work is given appropriate credit. Contents may not be used for commercial purposes, or adapted, remixed, transformed or built upon. (https://creativecommons.org/licenses/by-nc-nd/4.0/).

Thieme Medical and Scientific Publishers Pvt. Ltd. A-12, 2nd Floor, Sector 2, Noida-201301 UP, India 
on their own. In Indian subcontinent, traditional healers are one of the main service providers and most of those who believed in supernatural causation of epilepsy primarily consult indigenous healers. ${ }^{2,7-10}$ This often results in delay in initiation of antiepileptic treatment and many remain untreated in the community.

In view of this, it becomes imperative to generate more data regarding perception of the cause of epilepsy and subsequent help-seeking behavior in Indian population. This study aimed to explore the perception of the causes of illness and patterns of help-seeking behavior from the patient and their families, attending the outpatient department and indoor in a tertiary care hospital in Eastern India.

\section{Methods}

We conducted this study at a multispecialty teaching tertiary-care hospital that provides services to a major area in eastern state of India. We selected our subjects using the following criteria:

\section{Inclusion Criteria}

Participants who fulfilled the International League Against Epilepsy (ILAE) criteria, ${ }^{11}$ and were accompanied by a reliable informant and willing to participate in the study by providing answers to the questionnaire and providing an informed consent were included. Age was not a bar, but for subjects below 18 years, the accompanying parent was interrogated and his/her demographic profile was recorded after obtaining consent for participation.

\section{Exclusion Criteria}

Patients with a history of brain surgery or traumatic brain injury, concomitant nonantiseizure medication with central nervous system effects, drug abuse, and having other progressive medical, neurological, or psychiatric illness were excluded.

One hundred and fifty consecutive patients accompanied by a reliable informant or family member fulfilling the criteria were approached for consent. All the subjects consented to participate in the study.

Sociodemographic and clinical data of all the eligible subjects was collected. Perceived cause of illness and help-seeking pattern were explored from the patient and informant by administering proper instrument.

\section{Instruments}

The following instruments, as required, were used:

1. Sociodemo graphic profile sheet: It was used to record the relevant sociodemographic data on gender, education, marital status, and background (rural or urban).

2. Clinical profile sheet: It was used to record the following clinical details: diagnosis, duration of illness, most prominent symptoms, treatment history, etc.

3. Questionnaire for exploring perceived cause of illness: This was specifically designed for this study. The questionnaire was designed by the investigators after an extensive literature search. Prior to the study, it was pretested on a sample of 20 individuals. It was validated by the Machine Learning unit, Indian Statistical Institute, Kolkata; and accordingly, minor changes were made (unpublished data). Perceived causes were divided into two broad categories: causes inside the body and causes outside the body. The former was further subdivided into bodily pathology, habits/practices, and psychological causes, while the later consisted of supernatural causes. Among many responses stated by the patient "the predominant" one was considered as the response the patient considered having highest percentage of causal relationship with the disease, "spontaneous" one was considered which came out spontaneously, and "on probing" was the response they considered the right one from a group of multiple choices they were given by the interviewer.

4. Questionnaire for assessing pattern for help-seeking: This was also specifically designed for the study after extensive literature search. This included 24 types of help-seeking behavior. For information and analysis purposes, these responses were divided into two broad categories-professional medical help (which comprises government hospital, health clinic of nongovernment organization, private general practitioner, etc.) and nonprofessional help (comprises local herbal leader, faith-healer, Ojha, Gunin, astrologer, healing temple, dargah, Maulavi, priest, quack, etc.)

\section{Statistical Analysis}

Statistical tests were performed to find out the association between various perceived causes of illness and different types of help-seeking by using the SPSS software package for windows, version 20 (SPSS Inc., Chicago, Illinois, United States). Descriptive data was expressed in terms of percentage, mean, and range.

We computed the association of the perception and type of help-seeking behavior with chi-squared test, along with phi and lambda test as and when necessary as these are ordinal and nominal variables. We used Pearson chi-squared test $\left(\mathrm{X}^{2}\right)$ test to determine whether there is a statistically significant difference between the expected and observed frequencies of perception of the cause of epilepsy and help-seeking behavior. We also measured Cramer's V value $(\boldsymbol{\varphi c})$ to determine the association between the perception and help-seeking behavior. $\boldsymbol{\varphi c}$ varies from 0 (corresponding to no association between perception and help-seeking) to 1 (complete association) and can reach 1 only when each variable is completely determined by the other.

\section{Results}

\section{Sociodemographic Profile}

Among 150 patients, 67 (44.67\%) (38 boys and 29 girls) were below 18 years of age and their parents were interviewed. The age range of the patients participated in this study was between 3 and 65 years. Of those participated in the study, 82 were male and 68 were female, 92 were educated up to standard X, 37 were married, 46 were housewife or 
managing households, 48 were students, and 87 were from rural background (- Table $\mathbf{1}$ ). Forty-one of the respondents were illiterate.

\section{Clinical Profile}

Perceived Causes of Illness

The participants gave highly variable responses to the question that assessed their opinion about the cause of epilepsy. According to the respondent's perception, cause of epilepsy was divided into two broad categories, namely causes inside the body and causes outside the body. Causes inside the body were further divided into (i) bodily pathology, (ii) habits and practices, and (iii) psychological causes, whereas cause outside the body is considered as supernatural causes. Bodily pathology was further divided into following categories as per their perceptions: malfunction on dysfunction of specific organ system or organ, physical trauma, medical illness, operation, accidents, ingestion of poisonous food or drink, illness/accident/any event of mother during her pregnancy, birth trauma or distress, childhood illness, or stress. Habits and practices include masturbation, addiction of drugs and alcohol, visit to brothel, intake of any particular food, bad association or peer group, and pressure of study. Psychological causes include too much worry and anxiety, too much mental pressure, problems due to love affair, relational problem, and major accident or illness or bereavement of family member. Supernatural causes include gods and goddesses, stars and astronomy, bad spirit, black magic and witchcraft, harm caused by envious neighbor, karma or deeds of previous birth, and bad fortune.

The median number of responses endorsed by the respondents was 5 (range: $1-7$ ) (see - Table 2). A total $72 \%$ of the respondents spontaneously related "bodily pathology" as the perceived cause of epilepsy. The spontaneous response relating to "habits and practices" and "psychological" as the perceived causes were 3.88 and $23.37 \%$, respectively. Psychological cause was the predominant one in female in $12.98 \%$ and in case of male it was $2.59 \%$. On probing, $66.23 \%$ of the respondents ascribed supernatural cause as the perceived cause of epilepsy. In focal seizures, $25 \%$ of the female and $38 \%$ of the male ascribed "supernatural" factors as cause. However, only $13 \%$ of female and $14 \%$ of male respondents ascribed "supernatural" factors as their cause in case of generalized seizure. A total of $31.8 \%$ of female and $47.6 \%$ male respondents with focal seizure revealed "bodily pathology" as their causes, $56.5 \%$ female and $67.2 \%$ male with generalized seizure told "bodily pathology" as their causation, and $13 \%$ female and $14.7 \%$ male with generalized seizure had "supernatural" causation. Interestingly, 26\% female patients with generalized seizure ascribed "psychological" factors as causes.

\section{Help-Seeking Behavior}

Epilepsy patients sought treatment from different persons in their locality before reaching our institute. We divided these helps into five broad categories, namely (i) professional help, for example, primary health center, rural, subdivisional or district hospital, consultant neurologist, physician or psychiatrist, general practitioner, nursing home, mental health specialty, and health clinics run by nongovernmental organization; (ii) nonprofessional medical help, for example, local medical practitioner(not formally trained), and faith healer like gunin or ojha; (iii) religious remedies, for example, healing temple, dargah, priest or maulavi, and astrologer; (iv) alternative medicines, for example, homeopath, kabiraj, Ayurveda, Unani, and local herbal leader; and (v) others, for example, yoga, physical exercise, and meditation.

The median number of consultations sought by families of patients with epilepsy before reaching the tertiary care

Table 1 Demographic profile of patients

\begin{tabular}{|c|c|c|c|}
\hline & $\begin{array}{l}\text { Male } \\
n(\%)\end{array}$ & $\begin{array}{l}\text { Female } \\
n(\%)\end{array}$ & Total \\
\hline$n$ & $82(54.6)$ & $68(45.33)$ & 150 \\
\hline \multicolumn{4}{|l|}{ Marital status } \\
\hline Unmarried & $63(76.82)$ & $50(73.52)$ & $113(75.33)$ \\
\hline Married & $19(23.17)$ & $18(26.47)$ & $37(24.66)$ \\
\hline \multicolumn{4}{|l|}{ Educational status } \\
\hline Illiterate & $24(29.26)$ & $17(25)$ & $41(27.33)$ \\
\hline Up to standard $X$ & $47(57.31$ & $45(66.17)$ & $92(61.33)$ \\
\hline Beyond standard X & $11(13.41)$ & $6(8.82)$ & $17(11.33)$ \\
\hline \multicolumn{4}{|l|}{ Occupation } \\
\hline Employed & $28(34.14)$ & $4(5.88)$ & $32(21.33)$ \\
\hline $\begin{array}{l}\text { Housewife/ } \\
\text { Household work }\end{array}$ & $13(15.85)$ & $33(48.52)$ & $46(30.66)$ \\
\hline Student & $47(57.31)$ & $31(45.58)$ & $72(48)$ \\
\hline \multicolumn{4}{|l|}{ Background } \\
\hline Rural & $45(54.87)$ & $42(61.76)$ & $87(58)$ \\
\hline Urban & $37(45.12)$ & $26(38.23)$ & $63(42)$ \\
\hline
\end{tabular}


Table 2 Patients' perception about cause of epilepsy

\begin{tabular}{|c|c|c|c|}
\hline & Predominant (\%) & Spontaneous (\%) & On probing (\%) \\
\hline \multicolumn{4}{|c|}{ I. Causes inside the body } \\
\hline \multicolumn{4}{|c|}{ Bodily pathology } \\
\hline Male & 38.96 & 48.05 & 40.25 \\
\hline Female & 22.07 & 24.67 & 36.36 \\
\hline Total & 61.03 & 72.72 & 76.62 \\
\hline \multicolumn{4}{|c|}{ Habits and practices } \\
\hline Male & 2.59 & 2.59 & 3.89 \\
\hline Female & 1.29 & 1.29 & 1.29 \\
\hline Total & 3.88 & 3.88 & 5.18 \\
\hline \multicolumn{4}{|c|}{ Psychological } \\
\hline Male & 2.59 & 10.38 & 27.27 \\
\hline Female & 12.98 & 12.98 & 28.67 \\
\hline Total & 15.57 & 23.37 & 55.84 \\
\hline \multicolumn{4}{|c|}{ II. Causes outside the body } \\
\hline \multicolumn{4}{|c|}{ Supernatural causes } \\
\hline Male & 7.79 & 6.49 & 32.46 \\
\hline Female & 10.38 & 14.28 & 33,76 \\
\hline Total & 18.17 & 20.77 & 66.23 \\
\hline
\end{tabular}

center was 3 (range: $1-15$ ). About $80 \%$ of the patients sought professional medical help as their first help in preference to nonprofessional help (20\%). - Table 3 shows the help-seeking pattern of the families of persons with epileptic disorders.

It has been observed that female respondents sought a greater number of helps in comparison to male. Professional help-seeking is almost equal in both. Interestingly, female respondents were much more interested to visit nonprofessional than male ( 9.25 vs. 0.75 ). The similar picture has been observed in religious ( 1.75 vs. 0 ) and alternative medicine (2.5 vs. 0.25 ). None has sought "other" group of help.

Individual patient did not decide on their own about their help-seeking. Family played an important role in decision making. In most cases father, elder brother in the family or in some cases the neighbor took the decision. Before reaching to modern medical facilities, the female respondents spent 2.5 years on average in seeking help from other than professional help. In case of male, it was 1.7 years. Cost of treatment was another important issue. In nonprofessional, religious help, the patient expended between
50 to 500 rupees, while in professional help-seeking, it varied between 500 and 50,000 rupees.

From the - Table 3, it is evident that those who sought professional help, $87.67 \%$ of male and $76.27 \%$ of female had bodily pathology as perceived cause of illness. Similarly, $19.17 \%$ of male and $8.47 \%$ of female with thought that the disease was from habits and practices, $30.13 \%$ male and 55.93\% female with thought that it was from psychological cause, and $63.01 \%$ of male and $47.45 \%$ female thought that it was from supernatural cause sought professional help. While $16.43 \%$ male and $15.25 \%$ female of bodily pathological perception sought nonprofessional help, $15.06 \%$ male and $16.94 \%$ female of supernatural causation went to nonprofessional remedies. About $8.21 \%$ male and $6.77 \%$ female with bodily pathology and $6.84 \%$ male and $8.47 \%$ female of supernatural perception sought religious help. Very few respondents with other perception went for religious help. About $13.55 \%$ female of bodily pathology and equal number with supernatural perception went for alternative medicine. Patients of other perceptions seeking for other help were

Table 3 Patterns of help sought by patients having different perceptions about cause of epilepsy

\begin{tabular}{|l|l|l|l|l|l|l|l|l|l|}
\hline \multirow{2}{*}{ Types of help sought } & \multicolumn{3}{|c|}{ Perception of causes of epilepsy (\%) } \\
\cline { 2 - 11 } & \multicolumn{2}{|c|}{ Bodily pathology } & Habits and practices & \multicolumn{2}{|c|}{ Psychological } & \multicolumn{3}{c|}{ Supernatural } \\
\cline { 2 - 11 } & Male & Female & Male & Female & Male & Female & Male & Female \\
\hline Professional medical help & 87.67 & 76.27 & 19.17 & 8.47 & 30.13 & 55.93 & 63.01 & 47.45 \\
\hline $\begin{array}{l}\text { Nonprofessional medical } \\
\text { help }\end{array}$ & 16.43 & 15.25 & 2.73 & 1.69 & 6.84 & 11.86 & 15.06 & 16.94 \\
\hline Religious remedies & 8.21 & 6.66 & 2.73 & 3.38 & 4.10 & 5.08 & 6.84 & 8.47 \\
\hline Alternative medicine & 8.21 & 13.55 & 2.73 & 1.69 & 1.36 & 6.77 & 6.84 & 13.55 \\
\hline Others & 0 & 0 & 0 & 0 & 0 & 0 & 0 & 0 \\
\hline
\end{tabular}


insignificant in number. None of our respondents had practiced "other" help-seeking categories (yoga, physical exercise, meditation, etc.).

\section{Correlation of Help Sought with Perception about Cause of Epilepsy}

We tried to correlate predominant perceived cause of epilepsy and help-seeking pattern of our cohort (see - Table 4). Female respondents with supernatural perception sought nonprofessional help $(p=0.000)$, religious help $(p=0.004)$, and help from alternative medicine personnel $(\rho=0.001)$. Female respondents with psychological cause as perception sought help significantly from alternative medicine personnel $(p=0.016)$, from nonprofessional personnel $(p=0.023)$, religious people ( $p=0.048$ ), and also from professional person $(p=0.001)$. All other variables were insignificant. No relation was observed in male respondents' perception about cause of epilepsy and their different help-seeking behavior, except in male respondents with perception in bodily pathology-seeking nonprofessional help $(p<0.001)$, and male with supernatural belief-seeking religious remedies $(p=0.009)$.

\section{Discussion}

In this study, we attempted to explore peoples' belief about the causes of epilepsy and their preferred methods of help-seeking. Studies from developing as well as developed countries have suggested that general public attribute a wide range of nonbiomedical entities to the cause of epileptic disorders. ${ }^{2,12}$ There are very few studies from India regarding perceptions about the cause of epilepsy and subsequent help-seeking pattern..$^{3,410,13}$ Shorvon and Farmer in a landmark study observed that the key to improvements in medical treatment lies with better understanding of patients' cultural concepts of epilepsy and its treatment, along with other measures. ${ }^{2}$ Our cohort held a wide variety of beliefs regarding causation of epilepsy. We probed with questions as the patients often tried to conceal their disease. Our patients described different entities based on their beliefs about causes of their disease. These included demons capturing their soul, curse of gods, and some of their neighbors became envious and made witchcraft or black magic, etc. Some even argued in favor of bad fortune and their misdeeds in their previous life. Many of our patients believed in supernatural as well as psychological causes leading them to take help from traditional healers. Interestingly, female respondents sought nonprofessional, religious, and alternative medicine help much more than male respondents, although there was no difference of professional help-seeking between male and female respondents. It might suggest backwardness of women at large in the society that is an important barrier of modern medical treatment reaching to patients with epilepsy. ${ }^{6}$ Epilepsy being a hidden disease, the scale of the problem is by no means apparent at either the community or national level. ${ }^{5}$

It has been observed that most of the patients irrespective of gender, having no formal education, had a belief in supernatural causes. On the contrary, believers in other causes have diverse educational status. Cost and time spent in other modalities before professional help-seeking were significant as mentioned previously. Family and neighbors played a key role in decision making. ${ }^{14}$ So, individual perception, family decision, cultural belief, cost of the help, formal education all interacted in a complex manner in decision making,

Moreover, it has been revealed in the study that a significant proportion of respondents having focal seizure with or without secondary generalization and complex partial seizure believed in "supernatural" causation. Respondents with generalized seizure accepted "bodily pathology" as their causative factor. Patients with multiple seizure types and more frequent seizures were more prone to believe in multiple causation. Few of the believers in super natural causation had history of birth asphyxia (though the number is very few). All these may raise concern-whether this belief system is entirely a sociocultural product or any organic basis is there.

Regarding factors, poor knowledge, having no history of experiencing epileptic seizures, unfavorable attitudes, and poor social support might be associated with poor help-seeking behavior. Stigma may give rise to social isolation and poor social support that ultimately make help-seeking

Table 4 Correlation of pattern of help sought by patients with different perceptions of cause of epilepsy

\begin{tabular}{|c|c|c|c|c|c|c|c|c|}
\hline & \multicolumn{2}{|c|}{ Bodily pathology } & \multicolumn{2}{|c|}{ Habits and practices } & \multicolumn{2}{|c|}{ Psychological } & \multicolumn{2}{|c|}{ Supernatural } \\
\hline & Male & Female & Male & Female & Male & Female & Male & Female \\
\hline $\begin{array}{l}\text { Professional medical } \\
\text { help }\end{array}$ & $\mathrm{a}$ & $\begin{array}{l}0.00^{*} \\
(1.00)\end{array}$ & a & $0.342(1)$ & $a$ & $0.001^{*}(1)$ & $\mathrm{a}$ & $0.00^{*}(1)$ \\
\hline $\begin{array}{l}\text { Nonprofessional medi- } \\
\text { cal help }\end{array}$ & $\begin{array}{l}0.00^{*} \\
(1.00)\end{array}$ & $\begin{array}{l}0.00^{*} \\
(0.826)\end{array}$ & $\begin{array}{l}0.570 \\
(0.740)\end{array}$ & $0.324(1)$ & $\begin{array}{l}0.268 \\
(0.839)\end{array}$ & $\begin{array}{l}0.023^{*} \\
(0.800)\end{array}$ & $\begin{array}{l}0.548 \\
(0.612)\end{array}$ & $0.00 *(0.826)$ \\
\hline Religious remedies & $\begin{array}{l}0.097 \\
(0.695)\end{array}$ & $\begin{array}{l}0.004^{*} \\
(0.76)\end{array}$ & $\begin{array}{l}0.877 \\
(0.596)\end{array}$ & $0.324(1)$ & $\begin{array}{l}0.961 \\
(0.529)\end{array}$ & $\begin{array}{l}0.048^{*} \\
(0.771)\end{array}$ & $\begin{array}{l}0.009^{*} \\
(0.882)\end{array}$ & $0.004 *(0.768)$ \\
\hline Alternative medicine & $\begin{array}{l}0.441 \\
(0.594)\end{array}$ & $\begin{array}{l}0.001^{*} \\
(0.796)\end{array}$ & $\begin{array}{l}0.771 \\
(0.655)\end{array}$ & $0.324(1)$ & $\begin{array}{l}0.368 \\
(0.800)\end{array}$ & $\begin{array}{l}0.016^{*} \\
(0.813)\end{array}$ & $\begin{array}{l}0.230 \\
(0.702)\end{array}$ & $0.001 *(0.796)$ \\
\hline Others $\Phi$ & - & - & - & - & - & - & - & - \\
\hline
\end{tabular}

Significance testing by chi-squared tests $\left(\mathrm{X}^{2}\right)$ and correlation analysis by Cramer's $\vee$ test $\left(\boldsymbol{\varphi}_{c}\right)$ in parenthesis. Values with $\left({ }^{*}\right)$ are statistically significant $(p<0.05)$

$\Phi-$ Yoga, physical exercise, meditation.

aNo statistics are computed because professional medical help is a constant. 
difficult. Participants who have experienced another person's seizures might have seen different treatment options owing to frequent impact of seizures on the physical and emotional health of those patients. Attitude had a direct relationship with treatment-seeking behavior, particularly in rural communities, and sociocultural attitudes continue to have a negative impact on the management of the rural epilepsy. All these factors have a reciprocal relationship with the perception of causes of epilepsy. These factors affect the perception that in turn influences these factors. Our male respondents ascribed bodily pathology as the perceived cause of their illness more than female respondents in case of psychological and supernatural cause as perceived one female outnumbered male. In the community, biomedical concepts are much weaker in female. ${ }^{7}$ About $20.77 \%$ of the respondents spontaneously disclose their belief in supernatural causes. On probing, this percentage rose to $66.23 \%$ indicating the tendency to conceal their belief, as it was probably regarded as socially backward opinions.

All these have serious implications in the treatment of epilepsy leading to increasing treatment gap. Although not entirely uniform, the literature supports the statement by ILAE/IBE/WHO in their introduction to the global campaigns against epilepsy "Epilepsy out of the Shadows," that globally $85 \%$ of people with epilepsy are either inappropriately treated or not treated at all., 3,4,15

When a sufferer of epilepsy perceived it to be caused by something other than any bodily pathology, they often seek an alternative treatment than seeking for modern medical help. These make them vulnerable to maltreatment and they often become noncompliant to modern medical treatment. The belief and faith about the disease and its treatment are so engrained in the mindset of these people that they are difficult to overcome. These myths and beliefs are considered rational by the society and they pose important challenge for the health care provider as the disease remains untreated in a vast population of the country.

Prevailing concepts of etiology of epilepsy are diverse and significant proportion of our patients had unscientific concepts about it. Many of them tried to hide their perception, which they ultimately did on probing. Except biomedical or bodily pathology, other concepts about etiology of epilepsy had a negative impact on treatment-seeking behavior, ultimately leading to increase the treatment gap.

To improve the treatment gap in the society, health education of the masses is extremely warranted. Apart from false belief, other reasons for treatment gap, for example, level of health care development, economy, distance from health care facilities and supply of antiepileptic drugs, and a lack of prioritization, should also be dealt with. The combination of poverty, limited medical care, and additional beliefs coalesces to severely limit the lives of people with epilepsy. In addition to clinical interventions, stigma-reduction interventions are important for improving the lives of people with epilepsy. ${ }^{1,9,16}$

A further point for consideration concerns traditional healers. Epilepsy would appear to offer a good basis for cooperation between biologic and traditional medicine, particularly when neither may satisfactorily answer the needs of the patient alone. This cooperation should also help any treatment to be more culturally relevant.

This should help to ensure that these interventions are sustainable in the long term. In this regard, it may be appropriate to work with local or national governments in epilepsy service provision.

Future studies are required in large sample to understand the indigenous health belief system and how they influence help-seeking in patients with epilepsy. This has enormous public health importance particularly for those who are involved with policy formation.

\section{Limitations and Strength of the Study}

Our study was not without limitation. Primarily this being a hospital-based study with small sample size, the result cannot be extrapolated in general population. Second, we have not studied other factors pertaining to treatment gap in epilepsy, for example, health delivery system of that particular area and availability of free of cost medicines in primary health center. Moreover, multivariate analysis was not performed and thus potential confounding factors were not eliminated. However, we think our result gives an idea about prevailing perception and behavior of patient with epilepsy in the society.

\section{Funding \\ None.}

\section{Conflict of Interest}

None declared.

\section{References}

1 Atadzhanov M, Haworth A, Chomba EN, Mbewe EK, Birbeck GL. Epilepsy-associated stigma in Zambia: what factors predict greater felt stigma in a highly stigmatized population? Epilepsy Behav 2010;19(3):414-418

2 Shorvon SD, Farmer PJ. Epilepsy in developing countries: a review of epidemiological, sociocultural, and treatment aspects. Epilepsia 1988;29(Suppl 1):S36-S54

3 Sridharan R, Murthy BN. Prevalence and pattern of epilepsy in India. Epilepsia 1999;40(5):631-636

4 Bharucha NE. Epidemiology of epilepsy in India. Epilepsia 2003;44(Suppl 1):9-11

5 Meinardi H, Scott RA, Reis R, Sander JW; ILAE Commission on the Developing World. The treatment gap in epilepsy: the current situation and ways forward. Epilepsia 2001;42(1):136-149

6 Goel D, Dhanai JS, Agarwal A, Mehlotra V, Saxena V. Knowledge, attitude and practice of epilepsy in Uttarakhand, India. Ann Indian Acad Neurol 2011;14(2):116-119

7 Baviskar S, Bhagat V, Kirte R, Sharanabasavaraj Ms, Shantala J. Gender disparities in health seeking behavior of epilepsy patients in tertiary care facility of rural Karnataka. Curr Neurobiol 2011;2(2):113-116

8 Gelfand M. Epilepsy in the African. Cent Afr J Med 1957; 3(1):11-12

9 Hills M. Overcoming the stigma of epilepsy. Neurol Asia 2010;15(Supple 1):21-24

10 Sinha A, Mallik S, Sanyal D, Sengupta P, Dasgupta S. Healthcare-seeking behavior of patients with epileptic seizure disorders attending a tertiary care hospital, Kolkata. Indian J Community Med 2012;37(1):25-29 
11 Guidelines for epidemiologic studies on epilepsy. Commission on Epidemiology and Prognosis, International League Against Epilepsy. Epilepsia 1993;34(4):592-596

12 Radhakrishnan K, Pandian JD, Santhoshkumar T, et al. Prevalence, knowledge, attitude, and practice of epilepsy in Kerala, South India. Epilepsia 2000;41(8):1027-1035

13 Joshi HS, Mahmood SE, Bamel A, Agarwal AK, Shaifali I. Perception of epilepsy among the urban secondary school children of Bareilly district. Ann Indian Acad Neurol 2012;15(2):125-127
14 Das K, Banerjee M, Mondal GP, Devi LG, Singh OP, Mukherjee BB. Evaluation of socio-economic factors causing discontinuation of epilepsy treatment resulting in seizure recurrence: a study in an urban epilepsy clinic in India. Seizure 2007;16(7):601-607

15 Meyer AC, Dua T, Ma J, Saxena S, Birbeck G. Global disparities in the epilepsy treatment gap: a systematic review. Bull World Health Organ 2010;88(4):260-266

16 de Boer HM, Mula M, Sander JW. The global burden and stigma of epilepsy. Epilepsy Behav 2008;12(4):540-546 